\title{
Article
}

\section{Total Tumor Load of mRNA Cytokeratin 19 in the Sentinel Lymph Node as a Predictive Value of Axillary Lymphadenectomy in Patients with Neoadjuvant Breast Cancer}

\author{
Karla B. Peña ${ }^{1}$, Amillano Kepa ${ }^{2}$, Alba Cochs ${ }^{2}$, Francesc Riu ${ }^{1}$, David Parada ${ }^{1, *}$ and Josep Gumà ${ }^{2, *}$ \\ 1 Department of Pathology, Hospital Universitari de Sant Joan, Institut d'Investigació Sanitària Pere Virgili, \\ Universitat Rovira i Virgili, 43204 Reus, Spain; karlabeatriz.pena@grupsagessa.com (K.B.P.); \\ friu@grupsagessa.com (F.R.) \\ 2 Department of Oncology, Hospital Universitari de Sant Joan, Institut d'Investigació Sanitària Pere Virgili, \\ Universitat Rovira i Virgili, 43204 Reus, Spain; kamillano@grupsagessa.com (A.K.); \\ alba.cochs@grupsagessa.com (A.C.) \\ * Correspondence: david.parada@urv.cat (D.P.); jguma@grupsagessa.com (J.G.)
}

check for updates

Citation: Peña, K.B.; Kepa, A.; Cochs, A.; Riu, F.; Parada, D.; Gumà, J. Total Tumor Load of mRNA Cytokeratin 19 in the Sentinel Lymph Node as a Predictive Value of Axillary Lymphadenectomy in Patients with Neoadjuvant Breast Cancer. Genes 2021, 12, 77. https://doi.org/ 10.3390/genes12010077

Received: 14 November 2020

Accepted: 6 January 2021

Published: 8 January 2021

Publisher's Note: MDPI stays neutral with regard to jurisdictional clai$\mathrm{ms}$ in published maps and institutional affiliations.

Copyright: $\odot 2021$ by the authors. Licensee MDPI, Basel, Switzerland. This article is an open access article distributed under the terms and conditions of the Creative Commons Attribution (CC BY) license (https:// creativecommons.org/licenses/by/ $4.0 /)$.

\begin{abstract}
Although sentinel lymph node biopsy (SLNB) has proved to be able to diagnose axillary lymph node status safely and reliably, there is still not enough evidence to suggest that it can be used in patients who have undergone neoadjuvant chemotherapy (NAC) for lymph node-sparing surgery. The present study used molecular approaches to determine whether SLNB can be reliably used in patients who have been treated with NAC before SLN surgery, and whether the total tumor load of the SLN can be used as a predictive factor in axillary lymphadenectomy (ALD). We used one-step nucleic acid amplification (OSNA) to analyze a total of 111 consecutive patients who presented operable invasive breast carcinomas and who had been treated with NAC. SLN was positive in 55 patients and the identification rate was $100 \%$. In 9 of these 55 patients, ALD showed that other lymph nodes were also involved. In all of the other 46 patients, the only lymph node to be identified as positive was SLN. Metastasis was not found in any of the axillary lymph nodes in the isolated tumor cell group. The total tumor load, defined as the amount of cytokeratin 19 mRNA copy numbers in all positives SLN (copies $/ \mu \mathrm{L}$ ), showed three risk groups related to the possibility of positive non-sentinel nodes. OSNA is a diagnostic technique that is highly sensitive, specific, and reproducible and it can be used to analyze sentinel lymph nodes after NAC. Total tumor load may be able to help predict additional metastases in axillary lymphadenectomy.
\end{abstract}

Keywords: breast cancer; sentinel lymph node; nucleic acid amplification; OSNA; total tumor load; neoadjuvant chemotherapy; axillary lymphadenectomy

\section{Introduction}

Sentinel lymph node biopsy (SLNB) is a standard surgical procedure that can be used to diagnose axillary lymph node status in patients with clinically node-negative breast cancer. It is known to be safe and reliable, and has now replaced axillary lymphadenectomy (ALD) $[1,2]$. It has been pointed out that there is no need for the ALD in patients with low burdens of axillary disease [2-4], especially in those who only have micrometastatic disease [4], or if there are only one or two lymph nodes with macrometastases [4].

Neoadjuvant chemotherapy (NAC) is the standard treatment in patients with locally advanced or inflammatory breast cancer, and there is evidence to support its usefulness in the initial stages of the disease [5-8]. NAC is indicated in patients with tumors of $30 \mathrm{~mm}$ or even smaller, when conservative surgery is not possible. NAC has the following advantages: it turns an initial non-surgical breast cancer into one that is operable, it increases the number of conservative surgeries, it evaluates in vivo tumor sensitivity to chemotherapy treatment, it initiates early systemic treatment and it may be useful for translational research. 
Its potential downsides are that it is a systemic treatment, there is a risk of progression during treatment and the axillary staging is imprecise [5-8].

This study uses molecular methods to assess whether SLNB can be reliably used in patients treated with NAC before they undergo SLN mapping and surgery. Our findings for SLNB were also correlated with those for axillary lymphadenectomy. The total tumor load (TTL) of the sentinel lymph node results was also evaluated as a predictive factor of positive ALD status in NAC settings.

\section{Materials and Methods}

This prospective and descriptive cohort study was performed in patients with invasive breast carcinomas who had undergone neoadjuvant chemotherapy. The study protocol was reviewed and approved by the Clinical Ethics Committee (CEIC) of the Sant Joan University Hospital in Reus (registration number CEIC14/02/27/2PROJ1), and written informed consent was obtained from each subject in accordance with the 1964 Helsinki declaration and its subsequent amendments.

Between December 2010 and December 2017, one hundred and eleven patients who had been diagnosed with operable invasive breast carcinomas and who had been given neoadjuvant chemotherapy at the Sant Joan University Hospital in Reus underwent breast surgery and an intraoperative axillary lymph node study. The average age of the 111 patients was 55 years, and ranged from 29 to 84 years old. The general criteria for selecting patients were: invasive breast cancer clinical stage T2 and T3, clinically negative preoperative axilla by palpation and axillary ultrasound, cytokeratin 19 expression in breast tumor biopsy, and adequate understanding of surgery and adherence to follow-up standards. The exclusion criterion was negative cytokeratin 19 tumors in the preoperative breast biopsy. Those tumor cells that did not express CK 19 or whose CK 19 expression varied were regarded as being CK 19 negative. To detect SLN metastasis, the SLNs were assayed by one-step nucleic acid amplification (OSNA). The clinicopathological data collected included age, clinical tumor size, pathological tumor size, histological type, nuclear grade, tumor response to chemotherapy (Miller and Payne grading system [9]), axillary lymphadenectomy, estrogen receptor, progesterone receptor, HER2 status and Ki-67 nuclear expression (ICC-4 system for classifying invasive carcinoma). The cases were staged according to the TNM AJCC 8th edition [10].

\subsection{Sentinel Lymph Node Sampling}

A tracer technique was used to carry out the sentinel lymph node procedure for a single tumor and, before surgery, four $0.1 \mathrm{~mL}$ deposits were used for peritumoral intramammary injection, with a $370 \mathrm{MBq}$ technetium 99 m-labeled sulfur colloid. For multiple tumors, a tracer technique was used to carry out the sentinel lymph node procedure and, before surgery, four $0.1 \mathrm{~mL}$ deposits were used for intradermal periareolar injection, with a $370 \mathrm{MBq}$ technetium $99 \mathrm{~m}$-labeled sulfur colloid. Lymphatic mapping was performed on the day before surgery and also just a few hours before. The sentinel node was localized with an intraoperative $\gamma$ probe. After excision, all active lymph nodes were sent to pathology to be further assessed.

\subsection{One-Step Nucleic Acid Amplification Assay}

Fresh sentinel lymph node specimens were sent to the pathology department. Once the fatty tissue had been cut away, they were weighed and SLN was completely processed by one-step nucleic acid amplification assay. Afterwards, they were homogenized with lysis buffer solution $(4 \mathrm{~mL}$ ) (Lynorhag) and centrifuged at $12,200 \times g$ at room temperature. An automated gene amplification detection system that uses a reverse transcription loopmediated isothermal amplification method with RTLAMP was employed to analyze a $2-\mu \mathrm{L}$ sample of the supernatant and a byproduct of the reaction was used to detect the degree of amplification. After magnesium pyrophosphate had been precipitated, the change in turbidity was correlated with the CK19 mRNA copy number/ $\mu \mathrm{L}$ of the original lysate 
using a standard curve with three calibrators with different CK19 mRNA concentrations. The lymph nodes that weighed more than the specified maximum $(600 \mu \mathrm{g})$ were cut into two pieces or more and processed separately. As many as four samples were analyzed in one run. Using the calculated number of CK19 mRNA copies per $\mu \mathrm{L}$, the result was evaluated in terms of the cutoff level calculated by Tsujimoto et al. [11]. The OSNA copy numbers were turned into standard histological measures for lymph node metastasis in the following way: $<2.5 \times 10^{2}$ copies / $\mu \mathrm{L}$ of CK19 mRNA were considered to be non-metastasis, between $2.5 \times 10^{2}$ and $5 \times 10^{3}$ copies $/ \mu \mathrm{L}$ were considered to be micrometastases, and $>5 \times 10^{3}$ copies $/ \mu \mathrm{L}$ were considered to be macrometastases. The OSNA assay is sometimes inhibited by inhibitory materials, which results in false-negative $\left(<2.5 \times 10^{2}\right.$ copies $\left./ \mu \mathrm{L}\right)$ reactions that may be turned into positive $(>250$ copies $/ \mu \mathrm{L})$ reactions by simple dilution (1:10). However, the values of these reactions after dilution are less reliable for quantitative assessment and were evaluated as + inhibition (+I) (Isolated Tumor Cells (ITC)). The total tumor load (TTL) was calculated in each SLN, and TTL was defined as the amount of CK19 mRNA copies number in all positives SLN (copies/ $\mu$ L). In patients with positive SLN, axillary lymphadenectomy was performed during the same surgical procedure, according to the protocol established in our hospital, which includes axillary lymph node levels one and two.

\subsection{Statistical Analysis}

Baseline characteristics were given as absolute numbers (of patients) and percentages. Ages were compared using the Mann-Whitney test and all other variables with the Pearson Chi-square test. The Z-score was used to search for potential outliers. Confidence intervals (CI) were set at $95 \%$, and $p<0.05$ was considered to be statistically significant. Logistic regression analysis was used to determine how well the total tumor load at the SLN could explain positive results when non-SLNs were being assessed. Other explanatory variables were also used: age, clinical tumor size, pathological tumor size (pT) postneoadjuvant treatment, lymphatic invasion (Ly), estrogen receptor (ER) status, progesterone receptor (PgR) status, HER2 status, the number of positive SLNs, the Miller and Payne response index, axillary lymphadenectomy node status by histological examination, and the logarithm of total tumor load mRNA CK19 copy number at the SLNB measured by OSNA (Max CK19 copies). Receiver operating characteristic (ROC) curve analysis and area under the curve (AUC) were used to quantify the prediction performance of each variable. All of the analyses were performed with SPSS version 23 and $\mathrm{R}$ version 4.0.

\section{Results}

\subsection{Patient Characteristics and Pathological Findings}

In 104 patients (93.7\%), the tumor was invasive carcinoma of no special type and in 7 patients $(6.3 \%)$ it was special type invasive carcinoma (lobular $(2.7 \%)$; medullary $(1.8 \%)$; metaplastic $(0.9 \%)$; papillary $(0.9 \%)$. The ICC- 4 classification system for invasive carcinoma showed that luminal B was the most common type in 70 patients $(63.1 \%)$. The next most common type was triple negative in 20 patients $(18 \%)$, and then HER2 in 16 patients $(14.4 \%)$ and luminal $\mathrm{A}$ in 5 patients (4.5\%). The administration of neoadjuvant chemotherapy was carried out following the protocols of our hospital and at the discretion of the medical oncologist. The sequential scheme of chemotherapy consisted of a combination of anthracyclines and taxanes. The anthracyclines used were adriamycin and cyclophosphamide, at doses of $60 \mathrm{mg} / \mathrm{m}^{2}$ and $600 \mathrm{mg} / \mathrm{m}^{2}$, respectively, and in a regimen of four cycles every 21 days. Paclitaxel and docetaxel were the most widely used taxanes, at doses of $100 \mathrm{mg} / \mathrm{m}^{2}$ and $80 \mathrm{mg} / \mathrm{m}^{2}$, respectively. Patients over-expressing HER2 tumors received anthracyclines/taxanes and trastuzumab (Herceptin ${ }^{\circledR}$ ). Trastuzumab was administered in fourteen cycles at $6 \mathrm{mg} / \mathrm{m}^{2}$ every 21 days and/or pertuzumab at a total dose of $840 \mathrm{mg}$, divided into four cycles every 21 days. In addition to the anthracycline/taxane regimen, patients with triple-negative tumors received carboplatin. As far as response to chemotherapy was concerned, pathological response was complete in 38 tumors (34.2\%), partial in 
67 tumors (60.4\%), and non-existent in only 6 tumors (5.4\%) (three luminal B type and three triple negative type). The ICC-4 type invasive carcinoma with the best complete pathological response was HER-2 with 13 tumors (81.25\%). Follow-up time was $4.81 \pm 2.13$ years. Overall survival was $93.7 \%(95 \%$ CI $87.0 \%-97.2 \%)$. Breast cancer overall mortality was 3.6\% (95\%CI 1.2\%-9.5\%). Disease-free interval did not show a significant difference between the negative and positive sentinel node groups $(p>0.005)$. The comparison between the groups without axillary lymphadectomy and axillary lymphadenectomy did not show significant differences in the disease-free interval $(p>0.005)$. One patient showed axillary recurrence and seven patients died of breast cancer $(6.3 \%)$ (Table 1$)$.

Table 1. Characteristics of patients.

\begin{tabular}{|c|c|}
\hline Characteristics & No. \\
\hline Age (years) ** & $57(29.5-84.5)$ \\
\hline \multicolumn{2}{|l|}{ Histological type } \\
\hline No special type & $104(93.7 \%)$ \\
\hline Special type & $7(6.3 \%)$ \\
\hline \multicolumn{2}{|l|}{ Nuclear Grade } \\
\hline 2 & $44(39.6 \%)$ \\
\hline 3 & $67(60.4 \%)$ \\
\hline \multicolumn{2}{|l|}{ ICC- 4 type } \\
\hline Luminal A & $5(4.5 \%)$ \\
\hline Luminal B & $70(63.1 \%)$ \\
\hline HER2 positive & $16(14.4 \%)$ \\
\hline Triple negative & $20(18 \%)$ \\
\hline \multicolumn{2}{|c|}{ Pathological T classification (pT) } \\
\hline pT2 & $91(81.98 \%)$ \\
\hline pT3 & $20(18.02 \%)$ \\
\hline Estrogen receptors ${ }^{* *}$ & $70(0-97)$ \\
\hline Progesterone receptors ** & $6(0-80)$ \\
\hline \multicolumn{2}{|l|}{ HER-2 expression } \\
\hline Negative & $65(58.6 \%)$ \\
\hline Positive & $46(41.4 \%)$ \\
\hline $\mathrm{Ki}-67^{* *}$ & $43(26.5-64.5)$ \\
\hline \multicolumn{2}{|c|}{ Pathological response to chemotherapy } \\
\hline No response & $6(5.4 \%)$ \\
\hline Partial & $67(60.4 \%)$ \\
\hline Complete & $38(34.2 \%)$ \\
\hline
\end{tabular}

Data are summarized as $n(\%)$, or median [IQR] ${ }^{* *}$, as appropriate.

From the 111 patients, 216 sentinel lymph nodes were obtained and studied by the OSNA assay, an average of $1.96 \pm 0.923 \mathrm{SLN} /$ patient. Sentinel lymph nodes of the internal mammary chain were not detected. In 56 patients (50.45\%) the OSNA assay was negative. Of the remaining 55 patients (49.55\%) with positive SLN, there were $9(16.36 \%)$ ITC (total tumor load (TTL) less than 250 mRNA CK19 copies $/ \mu \mathrm{L}), 30(54.55 \%)$ micrometastases and 16 (29.09\%) macrometastases (TTL between 270 and 2,190,000 mRNA CK19 copies/ $\mu$ L). In 46 of these 55 patients $(83.63 \%)$, SLN was the only positive lymph node. In two $(6.67 \%)$ of the patients with micrometastases and in seven (43.75\%) of the patients with macrometastases, SLN and axillary lymphadenectomy were positive. No patients with ITC showed axillary lymph node metastases (Table 2).

Each explanatory variable was subject to univariate and multivariate logistic regression analyses to determine the prediction performance of non-SLN metastasis. The results are summarized in Table 3. All parameters are given for both pre- and post-treatment. There was a significant association between the TTL of the sentinel lymph nodes and 
non-SLN metastasis. The variables in univariate logistic analysis were analyzed with the Cragg-Uhler and McFadden analysis to determine whether they predicted non-SLN status. To prevent multicollinearity, we recognized positive axillary lymph nodes as the only variable related to SLN status (Table 3).

Table 2. Immunocytochemical type (ICC-4), sentinel lymph node and axillary lymphadenectomy $(n=111)$.

\begin{tabular}{|c|c|c|c|c|}
\hline & Luminal A & Luminal B & HER2 Expression & Triple Negative \\
\hline$n$ & 5 & 70 & 16 & 20 \\
\hline \multicolumn{5}{|l|}{ SLN } \\
\hline Positive & 2 & 41 & 7 & 5 \\
\hline Negative & 3 & 29 & 9 & 15 \\
\hline \multicolumn{5}{|l|}{ SLN positive } \\
\hline ITC & 0 & 7 & 1 & 1 \\
\hline Micrometastases & 2 & 19 & 6 & 3 \\
\hline Macrometastases & 0 & 15 & 0 & 1 \\
\hline \multicolumn{5}{|l|}{ ALD } \\
\hline Positive & 0 & 8 & 0 & 1 \\
\hline Negative & 2 & 33 & 7 & 4 \\
\hline \multicolumn{5}{|l|}{$\begin{array}{c}\text { Pathological } \\
\text { response }\end{array}$} \\
\hline No response & 0 & 3 & 0 & 3 \\
\hline Partial response & 4 & 52 & 3 & 8 \\
\hline Complete response & 1 & 15 & 13 & 9 \\
\hline
\end{tabular}

Abbreviations: SLN: sentinel lymph node; ALD: axillary lymphadenectomy.

Table 3. Univariate analysis.

\begin{tabular}{|c|c|c|c|c|c|c|c|}
\hline & ALD Negative & & & ALD Positive & & & \\
\hline & Mean & CI lower & CI upper & Mean & CI lower & CI upper & $p$ value \\
\hline Diagnostic age & 48.66 & 45.39 & 55.35 & 44.15 & 40.57 & 51.40 & 0.439 \\
\hline Miller-Payne & 4 & 3 & 5 & 3 & 2 & 3 & 0.080 \\
\hline Tumor diameter previous treatment $(\mathrm{mm})$ & 33 & 22.25 & 39.75 & 43.5 & 34.5 & 59.5 & 0.181 \\
\hline Tumor diameter after treatment (mm) & 5 & 0 & 0.15 & 30 & 12 & 34 & 0.026 \\
\hline Total Tumor Load & 680,000 & 352,500 & $3,875,000$ & $27,410,000$ & $11,530,000$ & $3,000,000$ & 0.043 \\
\hline
\end{tabular}

Abbreviations: ALD: axillar lymphadenectomy.

\subsection{ROC Analysis}

In Figure 1, the results of the ROC analysis for the prediction of non-SLN metastasis include the variables that were shown to be significant $(p<0.05)$ by the univariate logistic Cragg-Uhler and Mc Fadden analyses. In ROC analysis, the TTL of sentinel lymph nodes proved to be the most powerful predictor of non-SLN metastasis by the area under the ROC curve (AUC) (AUC: 0.74 for non-SLN metastasis).

\subsection{Correlation between Total Tumor Load and Positive Lymph Nodes in Axillar Lymphadenectomy}

The risk cohort indicates that the probability of finding positive lymph nodes in axillar lymphadenectomy was significantly increased. The analysis showed that most of the SLNs had similar TTL values (around 20,000 mRNA CK19 copies/ $\mu \mathrm{L}$ ) and that two patients had relatively low values of 500 mRNA CK19 copies $/ \mu \mathrm{L}$. The group analysis showed three groups in terms of TTL and the probability of lymph node metastasis in axillary lymphadenectomy: (a) a very low-risk group of axillary metastasis, with a TTL between 0 and 500 mRNA CK19 copies/ $\mu \mathrm{L}$ without axillary positivity; (b) a low-risk group of axillary metastasis, with a TTL between 501 and 10,000 mRNA CK19 copies/ $\mu \mathrm{L}$, a low probability of axillary positivity $(11.11 \%$ ) and a confidence interval of $1.95,36.07$; (c) a high-risk group of lymph node metastasis, with a TTL greater than 10,000 mRNA CK19 copies/ $\mu \mathrm{L}$, a high probability $(50 \%)$, and a confidence interval of $26.8,73.2$. 


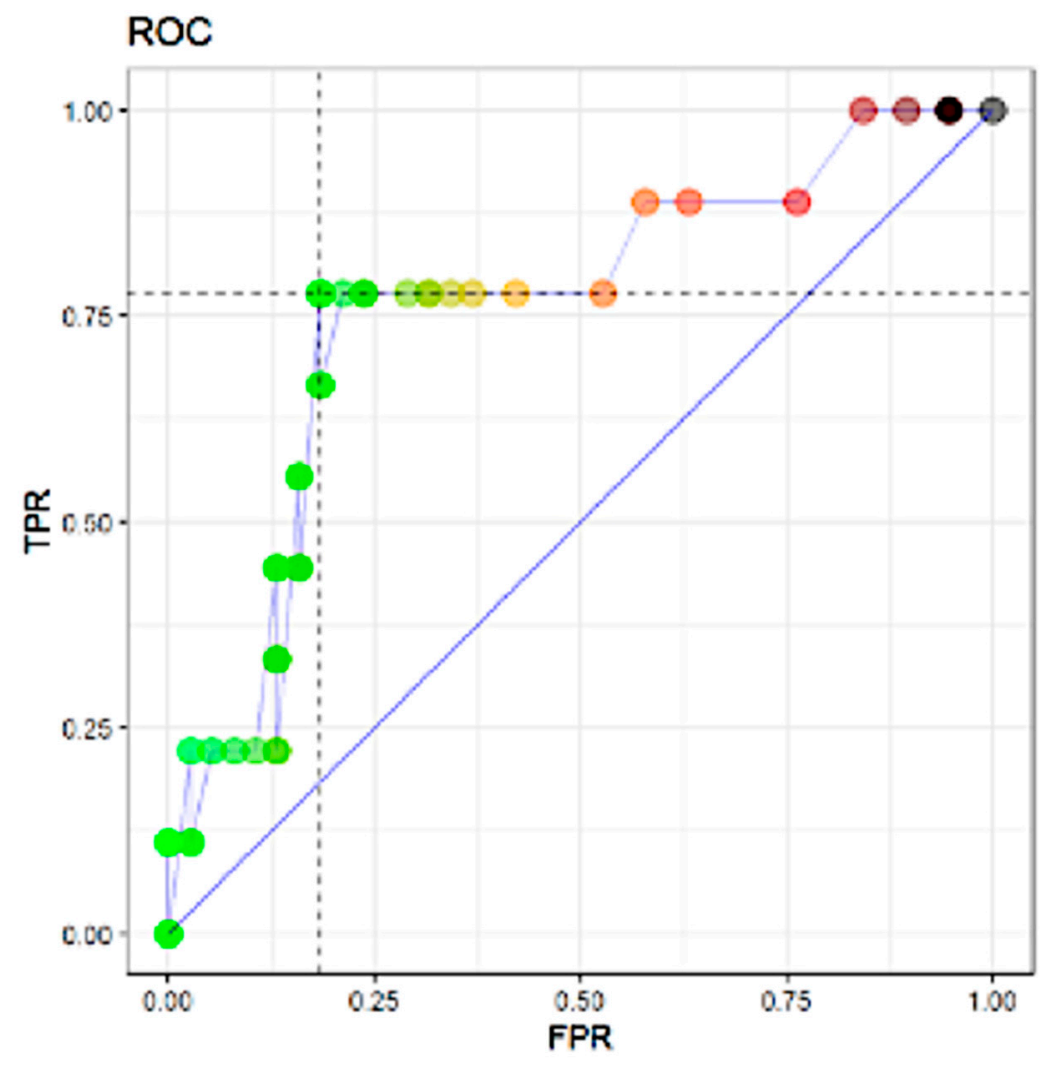

Figure 1. Area under the curve (AUC) 0.7602339. Abbreviations: TPR: true positive rate; FPR: false positive rate

\section{Discussion}

The SLNB technique is now the gold standard for the staging of axillary lymph node status in patients with breast cancer and has become the standard of care to reduce such upper limb morbidity as lymphoedema, shoulder stiffness and chronic pain, which are commonly linked to axillary lymphadenectomy $[2,11,12]$. One controversial issue is whether SLNB can be useful in patients who have previously been given chemotherapy. According to previous research, primary chemotherapy may modify the patterns of lymphatic drainage in the axilla [13-16] and the shrinkage of tumors may distort lymphatics if these patterns are aberrant [14-16]. Both these cases may affect whether SLNB is detected or not. Studies by individual institutions have reported sensitivity rates of $72-100 \%$ and false negative rates of $0-33 \%$ when SLNB is performed after neoadjuvant chemotherapy [15-23]. In the NSABP B-27 study and the French GANEA study, rates of identification were $85 \%$ and $90 \%$, respectively [15-23]. In our patients, the rate of identification was similar to that found by previous reports, which suggests that the ability to detect SLN is similar in all patients who have not undergone neoadjuvant chemotherapy.

With regard to the issue of whether analyzing SLNB after chemotherapy might make two surgical procedures unnecessary, the capacity of preoperative chemotherapy to provide a complete pathological response may exploit the down-staging effect of preoperative chemotherapy and reduce the number of patients who need axillary lymphadenectomy. Finally, it does not mean that preoperative chemotherapy can be delayed [17]. In the present study, OSNA was used to analyze all SLNs because it has an advantage over other conventional methods: it can quantitatively assess the TTL in SLNs when the lymph nodes detected are studied. In our study, patients with positive SLNs (ITC, and micro- and macrometastases) underwent axillary lymphadenectomy. Our results revealed that none of the nine patients with ITC had a positive lymph node after axillary lymphadenectomy, that the two patients with micrometastases showed positive lymph nodes after axillary lymphadenectomy, and that seven patients with macrometastases showed additional 
positive lymph nodes in axillary lymphadenectomy. This finding is interesting because it seems to suggest that, in patients with low TTL, axillary lymphadenectomy might be unnecessary. Our results support the stratification of the TTL and presence of positive lymph nodes in axillary lymphadenectomy into three risk groups: (1) a very low-risk group with a TTL less than or equal to 500 mRNA CK19 copies/ $\mu \mathrm{L}$; (2) a low-risk group with a TTL between 500 and 10,000 mRNA CK19 copies/ $\mu \mathrm{L}$; and (3) a high-risk group with a TTL greater than 10,000 mRNA CK19 copies/ $\mu \mathrm{L}$. Research has shown that the total tumoral load can be used to study SLNs and avoid unwanted surgical procedures [24-31].

The status of the axillary lymph nodes and the internal mammary chain is essential for regional staging and treatment choice. At present, internal mammary chain sentinel lymph node detection remains subject to debate due to ambiguous clinical relevance, and its indications have not been standardized in current guidelines [32] Different studies have shown that in breast cancer, approximately $30 \%$ of medial tumors and $15 \%$ of lateral tumors show primary lymphatic drainage to the internal mammary chain [33]. Another factor that may affect the detection rate of lymph nodes in the internal mammary chain may be related to the technique of administration of the tracer. Paredes et al. [34], demonstrated an overall detection rate of $14.1 \%$, but the detection rate improved when deep injection, both peritumoral and intratumoral, was used by $17 \%$. Qiu et al. [32] showed that the injection of radiotracer with a modified technique, periareolar intraperenchymal, with high volume and guided by ultrasound, can increase the detection of lymph nodes of the internal mammary chain by $71.1 \%$. In the present study, in patients with breast cancer and neoadjuvant chemotherapy, internal mammary chain drainage was not obtained. The difference in the detection rate between patients without and with NAC could be explained by the effect that NAC produces on the lymphatic drainage pattern [32]. It has been described that NAC could alter the lymphatic drainage patterns due to the contraction to fibrosis of the lymphatic vessels, as well as the obstruction of the lymphatic channels with cellular material or tumor embolisms [32]. However, research in the lymphatic drainages in the mammary chains after NAC have been limited. Studies are required in order to determine the detection capacity of the lymph nodes of the internal mammary chain, in the context of NAC.

Currently, NAC in breast cancer has been accepted as a standard therapeutic procedure for patients with different selection criteria such as: clinical lymph node involvement, tumor size $>2 \mathrm{~cm}$, triple-negative breast cancer, HER2-positive breast cancer, high proliferation index carcinoma, unresectable breast cancer tumors and inflammatory breast carcinoma [35]. Within this group of patients with breast cancer and no axillary lymph node metastases (N0), sentinel lymph node biopsy has been shown to be a safe procedure and can prevent unnecessary axillary lymphadenectomy [36-38]. There is no doubt that the efficacy of NAC has shown benefits in terms of overall survival and progression-free survival. Thus, the GANEA 2 study showed that 3-year DFS and OS were 94.8\% (95\% CI 91\%-97.1\%) and 97.8\% (95\% CI 94.9\%-99.1\%), respectively [36]. Our work showed similar results in terms of overall survival $(93.7 \%(95 \% \mathrm{CI} 87.0 \%-97.2 \%))$ and breast cancer overall mortality (3.6\% (95\%CI 1.2\%-9.5\%)), with a follow-up time of $4.81 \pm 2.13$ years.

Our study has several limitations. First, the number of patients analysed was not sufficient for firm conclusions to be drawn. Nevertheless, we think that it is still meaningful because we were able to show the accuracy and sensitivity of OSNA in SLN analysis, in the context of NAC. Furthermore, the TTL, assessed by OSNA, can help to predict the likelihood of more axillary metastases in NAC breast cancer. TTL is automatized, reproducible, assessed intraoperatively and not correlated with the type of surgery, and/or the histological tumor subtype and/or neoadjuvant chemotherapy. The high inclusion rate of luminal B invasive carcinoma could be considered a bias, although the patients included represent a real sample of the population in NAC breast cancer. Another clear limitation is that OSNA must be used and it is often not available. However, the use of molecular methods is recommended for better prognosis [10]. 


\section{Conclusions}

We have demonstrated that whole SLN analysis by OSNA is a highly sensitive, specific and reproducible diagnostic technique in sentinel lymph nodes after clinical node-negative breast cancer patients have undergone neoadjuvant chemotherapy and that TTL can help to predict additional non-SLN metastases in three different risk groups. However, further studies on a larger number of patients are needed to establish a new nomogram, which includes the results of the OSNA assay.

Author Contributions: Conceptualization: D.P.; Formal Analysis: D.P., K.B.P., J.G.; Data curation: D.P., K.B.P., J.G., A.K., A.C.; Writing—original draft: D.P., K.B.P., J.G.; Writing—review and editing: D.P., F.R.; Supervision: D.P.; Visualization: F.R.; Resources: A.K., A.C. All authors have read and agreed to the published version of the manuscript.

Funding: This research received no external funding.

Institutional Review Board Statement: The study was conducted according to the guidelines of the Declaration of Helsinki, and approved by the Ethics Committee of the Sant Joan University Hospital in Reus (CEIC14/02/27/2PROJ1, 27 February 2014).

Informed Consent Statement: Informed consent was obtained from all subjects involved in the study.

Data Availability Statement: Data is contained within the article.

Conflicts of Interest: The authors declare no conflict of interest.

\section{References}

1. Lyman, G.H.; Somerfield, M.R.; Bosserman, L.D.; Perkins, C.L.; Weaver, D.L.; Giuliano, A.E. Sentinel Lymph Node Biopsy for Patients with Early-Stage Breast Cancer: American Society of Clinical Oncology Clinical Practice Guideline Update. J. Clin. Oncol. 2017, 35, 561-564. [CrossRef] [PubMed]

2. Manca, G.; Rubello, D.; Tardelli, E.; Giammarile, F.; Mazzarri, S.; Boni, G.; Chondrogiannis, S.; Marzola, M.C.; Chiacchio, S.; Ghilli, M.; et al. Sentinel Lymph Node Biopsy in Breast Cancer: Indications, Contraindications, and Controversies. Clin. Nucl. Med. 2016, 41, 126-133. [CrossRef] [PubMed]

3. Wong, W.; Rubenchik, I.; Nofech-Mozes, S.; Slodkowska, E.; Parra-Herran, C.; Hanna, W.M.; Lu, F.-I. Intraoperative Assessment of Sentinel Lymph Nodes in Breast Cancer Patients Post-Neoadjuvant Therapy. Technol. Cancer Res. Treat. 2019, 18, 1533033818821104. [CrossRef] [PubMed]

4. Giuliano, A.E.; Ballman, K.V.; McCall, L.; Beitsch, P.; Brennan, M.B.; Kelemen, P.R.; Ollila, D.W.; Hansen, N.M.; Whitworth, P.; Blumencranz, P.W.; et al. Effect of Axillary Dissection vs No Axillary Dissection on 10-Year Overall Survival Among Women With Invasive Breast Cancer and Sentinel Node Metastasis: The ACOSOG Z0011 (Alliance) Randomized Clinical Trial. JAMA 2017, 318, 918-926. [CrossRef]

5. Mieog, J.S.D.; Van Der Hage, J.A.; Van De Velde, C.J.H. Neoadjuvant chemotherapy for operable breast cancer. BJS 2007, 94, 1189-1200. [CrossRef]

6. Van Der Hage, J.H.; Van De Velde, C.C.; Mieog, S.J. Preoperative chemotherapy for women with operable breast cancer. Cochrane Database Syst. Rev. 2007, 2007, CD005002. [CrossRef]

7. Li, X.; Wang, M.; Wang, M.; Yu, X.; Guo, J.; Sun, T.; Yao, L.; Zhang, Q.; Xu, Y. Predictive and Prognostic Roles of Pathological Indicators for Patients with Breast Cancer on Neoadjuvant Chemotherapy. J. Breast Cancer 2018, 22, 497-521. [CrossRef]

8. De Barros, A.C.S.D.; Paulo, M.H.B.P.D.S.; De Andrade, D.A. Extended Sentinel Node Biopsy in Breast Cancer Patients who Achieve Complete Nodal Response with Neoadjuvant Chemotherapy. Eur. J. Breast Health 2020, 16, 99-105. [CrossRef]

9. Ogston, K.N.; Miller, I.D.; Payne, S.; Hutcheon, A.W.; Sarkar, T.K.; Smith, I.; Schofield, A.; Heys, S.D. A new histological grading system to assess response of breast cancers to primary chemotherapy: Prognostic significance and survival. Breast 2003, 12, 320-327. [CrossRef]

10. Byrd, D.R.; Carducci, M.A.; Compton, C.C.; Fritz, A.G.; Greene, F.L. (Eds.) AJCC Cancer Staging Manual, 8th ed.; Springer: New York, NY, USA, 2017.

11. Tsujimoto, M.; Nakabayashi, K.; Yoshidome, K.; Kaneko, T.; Iwase, T.; Akiyama, F.; Kato, Y.; Tsuda, H.; Ueda, S.; Sato, K.; et al. One-step Nucleic Acid Amplification for Intraoperative Detection of Lymph Node Metastasis in Breast Cancer Patients. Clin. Cancer Res. 2007, 13, 4807-4816. [CrossRef]

12. Mansel, R.E.; Fallowfield, L.; Kissin, M.; Goyal, A.; Newcombe, R.G.; Dixon, J.M.; Yiangou, C.; Horgan, K.; Bundred, N.; Monypenny, I.; et al. Randomized Multicenter Trial of Sentinel Node Biopsy Versus Standard Axillary Treatment in Operable Breast Cancer: The ALMANAC Trial. J. Natl. Cancer Inst. 2006, 98, 599-609. [CrossRef] [PubMed] 
13. Purushotham, A.D.; Upponi, S.; Klevesath, M.B.; Bobrow, L.; Millar, K.; Myles, J.P.; Duffy, S.W. Morbidity After Sentinel Lymph Node Biopsy in Primary Breast Cancer: Results from a Randomized Controlled Trial. J. Clin. Oncol. 2005, 23, 4312-4321. [CrossRef] [PubMed]

14. Bleiweiss, I.J. Sentinel lymph nodes in breast cancer after 10 years: Rethinking basic principles. Lancet Oncol. 2006, 7, 686-692. [CrossRef]

15. Benson, J.R.; Jatoi, I. Sentinel lymph node biopsy and neoadjuvant chemotherapy in breast cancer patients. Future Oncol. 2014, 10, 577-586. [CrossRef] [PubMed]

16. Kuehn, T.; Bauerfeind, I.; Fehm, T.; Fleige, B.; Hausschild, M.; Helms, G.; Lebeau, A.; Liedtke, C.; Von Minckwitz, G.; Nekljudova, V.; et al. Sentinel-lymph-node biopsy in patients with breast cancer before and after neoadjuvant chemotherapy (SENTINA): A prospective, multicentre cohort study. Lancet Oncol. 2013, 14, 609-618. [CrossRef]

17. Fisher, B.; Brown, A.; Mamounas, E.; Wieand, S.; Robidoux, A.; Margolese, R.G.; Cruz, A.B.; Fisher, E.R.; Wickerham, D.L.; Wolmark, N.; et al. Effect of preoperative chemotherapy on local-regional disease in women with operable breast cancer: Findings from National Surgical Adjuvant Breast and Bowel Project B-18. J. Clin. Oncol. 1997, 15, 2483-2493. [CrossRef]

18. Gianni, L.; Baselga, J.; Eiermann, W.; Porta, V.G.; Semiglazov, V.F.; Lluch, A.; Zambetti, M.; Sabadell, D.; Raab, G.; Cussac, A.L.; et al. Phase III Trial Evaluating the Addition of Paclitaxel to Doxorubicin Followed by Cyclophosphamide, Methotrexate, and Fluorouracil, As Adjuvant or Primary Systemic Therapy: European Cooperative Trial in Operable Breast Cancer. J. Clin. Oncol. 2009, 27, 2474-2481. [CrossRef]

19. Mamounas, E.P.; Brown, A.; Anderson, S.; Smith, R.; Julian, T.; Miller, B.; Bear, H.D.; Caldwell, C.B.; Walker, A.P.; Mikkelson, W.M.; et al. Sentinel Node Biopsy After Neoadjuvant Chemotherapy in Breast Cancer: Results From National Surgical Adjuvant Breast and Bowel Project Protocol B-27. J. Clin. Oncol. 2005, 23, 2694-2702. [CrossRef]

20. Nason, K.S.; Anderson, B.O.; Byrd, D.R.; Dunnwald, L.K.; Eary, J.F.; Mankoff, D.A.; Livingston, R.; Schmidt, R.A.; Jewell, K.D.; Yeung, R.S.; et al. Increased false negative sentinel node biopsy rates after preoperative chemotherapy for invasive breast carcinoma. Cancer 2000, 89, 2187-2194. [CrossRef]

21. Tafra, L.; Verbanac, K.M.; Lannin, D.R. Preoperative chemotherapy and sentinel lymphadenectomy for breast cancer. Am. J. Surg. 2001, 182, 312-315. [CrossRef]

22. Parada, D.; Peña, K.B.; Riu, F.F.; Aguilar, A.E.; Cohan, S. Intraoperative molecular analysis of sentinel lymph nodes following neoadjuvant chemotherapy in patients with clinical node negative breast cancer: An institutional study. Mol. Clin. Oncol. 2016, 5, 507-510. [CrossRef] [PubMed]

23. Geng, C.; Chen, X.; Pan, X.; Li, J. The Feasibility and Accuracy of Sentinel Lymph Node Biopsy in Initially Clinically NodeNegative Breast Cancer after Neoadjuvant Chemotherapy: A Systematic Review and Meta-Analysis. PLoS ONE 2016, 11, e0162605. [CrossRef]

24. Buchholz, T.A.; Lehman, C.D.; Harris, J.R.; Pockaj, B.A.; Khouri, N.; Hylton, N.F.; Miller, M.J.; Whelan, T.; Pierce, L.J.; Esserman, L.J.; et al. Statement of the Science Concerning Locoregional Treatments After Preoperative Chemotherapy for Breast Cancer: A National Cancer Institute Conference. J. Clin. Oncol. 2008, 26, 791-797. [CrossRef] [PubMed]

25. Ohi, Y.; Umekita, Y.; Rai, Y.; Yotsumoto, D.; Matsukata, A.; Baba, S.; Tamada, S.; Matsuyama, Y.; Ando, M.; Sasaki, M.; et al. Whole sentinel lymph node analysis by a molecular assay predicts axillary node status in breast cancer. Br. J. Cancer 2012, 107, 1239-1243. [CrossRef] [PubMed]

26. Pegł, V.; Espinosa-Bravo, M.; Vieites, B.; Vilardell, F.; Antúnez, J.R.; De Salas, M.S.; Delgado-Sánchez, J.J.; Pinto, W.; Gozalbo, F.; Petit, A.; et al. Intraoperative molecular analysis of total tumor load in sentinel lymph node: A new predictor of axillary status in early breast cancer patients. Breast Cancer Res. Treat. 2013, 139, 87-93. [CrossRef] [PubMed]

27. Rubio, I.T.; Espinosa-Bravo, M.; Rodrigo, M.; Diaz, M.A.V.; Hardisson, D.; Sagasta, A.; Dueñas, B.; Peg, V. Nomogram including the total tumoral load in the sentinel nodes assessed by one-step nucleic acid amplification as a new factor for predicting nonsentinel lymph node metastasis in breast cancer patients. Breast Cancer Res. Treat. 2014, 147, 371-380. [CrossRef]

28. Piñero-Madrona, A.; Ripoll-Orts, F.; Sánchez-Méndez, J.I.; Chaves-Benito, A.; La Bárcena, M.R.G.-D.; Calatrava-Fons, A.; MenjónBeltrán, S.; Peg-Cámara, V. External validation of a prognostic model based on total tumor load of sentinel lymph node for early breast cancer patients. Breast Cancer Res. Treat. 2020, 181, 339-345. [CrossRef]

29. Cuffolo, G.; Msc, H.K.G.; Smith, B. One-step nucleic acid amplification CK19 copy number for sentinel node biopsy in breast cancer: Identification of new cutoffs to predict nonsentinel axillary node involvement. Breast J. 2020, 26, 2002-2005. [CrossRef]

30. Sansano, I.; Vieites, B.; De Salas, M.S.; García, C.; Amendoeira, I.; Bernet, L.; Pérez-García, J.M.; Espinosa-Bravo, M.; Rubio, I.T.; Cajal, S.R.Y.; et al. Axillary staging based on molecular analysis: Results of the B-CLOSER-II study. Pathol.-Res. Prat. 2020, 216, 153197. [CrossRef]

31. Fougo, J.L.; Amendoeira, I.; Brito, M.J.; Correia, A.P.; Gonçalves, A.; Honavar, M.; Machado, A.; Magalhães, A.; Marta, S.; Nogueira, M.; et al. Sentinel node total tumour load as a predictive factor for non-sentinel node status in early breast cancer patients -The porttle study. Surg. Oncol. 2020, 32, 108-114. [CrossRef]

32. Qiu, P.-F.; Zhao, R.-R.; Wang, W.; Sun, X.; Chen, P.; Liu, Y.-B.; Liu, Z.-G.; Wang, Y.-S. Internal Mammary Sentinel Lymph Node Biopsy in Clinically Axillary Lymph Node-Positive Breast Cancer: Diagnosis and Implications for Patient Management. Ann. Surg. Oncol. 2019, 27, 375-383. [CrossRef] [PubMed]

33. Manca, G.; Volterrani, D.; Mazzarri, S.; Duce, V.; Svirydenka, A.; Giuliano, A.; Mariani, G. Sentinel lymph node mapping in breast cancer: A critical reappraisal of the internal mammary chain issue. Q. J. Nucl. Med. Mol. Imaging 2014, 58, 114-126. [PubMed] 
34. Paredes, P.; Vidal-Sicart, S.; Zanón, G.; Pahisa, J.; Fernandez, P.L.; Velasco, M.; Santamaría, G.; Ortín, J.; Duch, J.; Pons, F. Clinical relevance of sentinel lymph nodes in the internal mammary chain in breast cancer patients. Eur. J. Nucl. Med. Mol. Imaging 2005, 32, 1283-1287. [CrossRef]

35. Colomer, R.; Saura, C.; Sánchez-Rovira, P.; Pascual, T.; Rubio, I.T.; Burgués, O.; Marcos, L.; Rodríguez, C.A.; Martín, M.; Lluch, A. Neoadjuvant Management of Early Breast Cancer: A Clinical and Investigational Position Statement. Oncology 2019, $24,603-611$. [CrossRef]

36. Classe, J.-M.; Loaec, C.; Gimbergues, P.; Alran, S.; De Lara, C.T.; Dupre, P.F.; Rouzier, R.; Faure, C.; Paillocher, N.; Chauvet, M.P.; et al. Sentinel lymph node biopsy without axillary lymphadenectomy after neoadjuvant chemotherapy is accurate and safe for selected patients: The GANEA 2 study. Breast Cancer Res. Treat. 2019, 173, 343-352. [CrossRef]

37. Mathelin, C.; Lodi, M. Narrative review of sentinel lymph node biopsy in breast cancer: A technique in constant evolution with still numerous unresolved questions. Chin. Clin. Oncol. 2020, 9, 5. [CrossRef]

38. Qiu, S.-Q.; Zhang, G.; Jansen, L.; De Vries, J.; Schröder, C.P.; De Vries, E.G.; Van Dam, G.M. Evolution in sentinel lymph node biopsy in breast cancer. Crit. Rev. Oncol. 2018, 123, 83-94. [CrossRef] 